Association for Information Systems

AIS Electronic Library (AISeL)

ICEB 2011 Proceedings

International Conference on Electronic Business

(ICEB)

Winter 12-2-2011

\title{
Assessing The Global E-Readiness Of Hotel Chain Websites
}

Peter O'Connor

Follow this and additional works at: https://aisel.aisnet.org/iceb2011

This material is brought to you by the International Conference on Electronic Business (ICEB) at AIS Electronic Library (AISeL). It has been accepted for inclusion in ICEB 2011 Proceedings by an authorized administrator of AIS Electronic Library (AISeL). For more information, please contact elibrary@aisnet.org. 


\section{Assessing the Global e-Readiness of Hotel Chain Websites \\ Peter O’Connor, Essec Business School, oconnor@essec.fr}

\begin{abstract}
Companies serving a truly global customer base need to adapt their websites to take the linguistic, culture and social differences of local markets into account. This study benchmarks the efforts of hotel chains to incorporate appropriately adapted content and facilities on their consumer websites as an indicator of their commitment to servicing international markets. Both individual findings and the summary Global e-Readiness Index suggest that most are not acting global in their e-commerce efforts. While many provide content in languages other than English, even the highest performers fail to take their internationalization efforts deep enough into the purchase process to facilitate purchases by international clients.
\end{abstract}

Keywords: e-Commerce, Globalization, Hotel sector

\section{INTRODUCTION}

Although lacking an agreed definition, e-commerce has become a key characteristic of modern society (Good \& Schultz, 2002). Many businesses use e-commerce, in particular the medium of the Internet, to inform, interact with, and sell to customers all over the world [33]. As countless researchers have pointed out, the growth of the Internet as an information and commercial medium allows any company, regardless of its size or location, to reach out and transact with customers globally [8]. However, with many e-commerce efforts originating in the United States [35], a question mark arises over how well companies are prepared to cater to the global nature of e-commerce [18]. While in the past the majority of Internet users (and thus potential shoppers) resided in North America, web demographics are quickly changing, with Asian, African and Arab countries growing rapidly in terms of both Internet penetration and e-commerce revenues [13].

In relation to their e-commerce efforts, Bin et al claimed that "most American companies are so focused on their domestic market that they do not pay any attention to overseas" [6]. Quoting statistics from both IDC and from Forrester Research, they show that more than half of websites surveyed were doing little to internationalize their content; that many leading websites were turning away orders originating from outside the US; and that three-quarters of websites were not designed to handle non-US addresses or calculate non-US shipping costs [6]. While this may have been acceptable when the majority of e-commerce was being conducted within the USA, more recent statistics indicate that over sixty percent of e-commerce transactions now have at least one international (i.e. non-U.S.) party [33]). Being able to exploit this opportunity is highly dependent on having adapted to the needs of international markets [25].
Given the importance of selling in foreign countries for the travel sector, this paper sets out to explore if the major hotel chains are prepared to service clients from international markets on their consumer websites. Having examined the literature, the websites of the largest fifty companies are critically evaluated as to their suitability for use by non-US based consumers. Their Global e-Readiness Index (GRI) - a quantitative metric developed to assess a website preparedness to interact with a global audience is subsequently calculated [2]. Recommendations as to how websites could be improved are subsequently presented.

\section{BACKGROUND}

In an era where the world is essentially flat, firms operate in a global environment [15]. This is especially true of companies in the travel industry, as their customers typically come from all over the world. Thus the growth of the Web as a communications and commercial medium with worldwide reach would seem to offer great potential. By drastically reducing the importance of proximity, e-commerce helps companies to connect with people across borders with ease [32]. However, having the entire world as potential customers does not necessarily translate into being able to do business effectively on a global basis [3]. The challenges of operating globally are not trivial, given "the existence of around two hundred and thirty counties, over six thousand languages, one hundred and forty seven currencies and innumerable cultures and sub-cultures" [5, p 33].

Both the International Business and the International Marketing literature debate the merits of standardization versus adaptation strategies when addressing global markets [10]. Although standardization provides advantages in terms of lower costs, research has shown that in the electronic arena websites that use a standardized approach tend to be less able to compete with ones that use a local or regional strategy [31]. From the consumer perspective, multiple studies have also shown that country of origin affects both visitors' usage and their perceptions of web sites (see, for example, [9]; [21]; [36] or [27]). Most researchers agree that having a global audience "necessitates country-specific cultural adaptation" [39]. Therefore companies, particularly those in the service sector, that wish to be global players must adapt and tailor their web presence to the specific needs of clientele in each market.

To achieve this, the e-commerce literature suggests a number of inter-related issues that must be addressed. The most obvious is language [24]. While in the past the majority of Internet users resided in the US and for the most part spoke English [7], Anglophones now account for less than one-third of Internet users. Although English is the official language of nearly eighty countries, it is the native language of only seven 
[30]. In addition, the number of non-Anglophones Internet users is growing rapidly. Despite this, the majority of Web pages remain in English [24].

Research has shown that a key element for e-commerce success is addressing markets in their native language [24]. For example, Forrester Research (2003) maintain that consumers spend nearly twice as much time, and are three times more likely to buy, on websites presented in their own language. Similarly, having surveyed Chinese, American, Egyptian and German consumers from an epistemological perspective, Seidenspinner \& Thuner [33] maintain that translation of an entire website into the local language is highly advisable if a company wants to effectively address a particular market. Blended approaches - with part of the content presented in the native language and part in English represent a reasonable, but less effective, compromise [33].

However linguistic translation is a relatively minor issue adapting a website to meet the challenges of a global marketplace is more complicated. In particular the culture of local markets has a massive effect [9]. Culture can be defined as a shared set of values that influence societal perceptions, attitudes, preferences and responses [32]. Dutch cultural anthropologist Geert Hofstede [17] identified five dimensions of culture (power distance; collectivism vs. individualism; femininity vs. masculinity; uncertainty avoidance; and longvs short-term orientation) which have subsequently been used by other authors to investigate the effect of cultural differences on e-commerce (see, for example, [28], [25] or [9]). While web content can be linguistically translated relatively easily, adapting to these issues is more difficult.

Several studies have specifically investigated the relationship between cultural factors and e-commerce variables such as website design, online shopping behavior and trust in an e-commerce context. Most highlight how significant attitudinal differences exist as regards online shopping between different regions of the world [34] - especially between western consumers and others [13]. For example, Seidenspinner \& Thuner [33] maintain that users' cultural preferences impact their preferred navigation tools, perceived quality of page design as well as how consumers perceive and process information provided online. Similarly, Del Galdo and Nielsen [11] demonstrated how screen design directions have different psychological and social associations in different cultures, causing users to have different shopping experiences. Dong \& Salvendy [12] continue this theme by demonstrating how vertically web menus for Chinese v.s. horizontally menus for US consumers increase performance and satisfaction due to the differences in the writing styles - i.e. top-down vs. left-to-right - in the two regions.

On a macro level, Kim \& Lee [22] showed how different components of WebQual (particularly integrated communications, trust and innovativeness) affect the satisfaction and purchase intent of online shoppers in the US and Korea in different ways. In a similar study, Hwang, Jung \& Salvendy [19] found that Korean consumers are more concerned about trust and security than consumers in either the US or Turkey. Chau et al [9] found that US consumers preferred websites to directly provide information about their products, in contrast to the more social network approach preferred by respondents from Hong Kong. In contrast to direct sales pitches, the latter prefer information provided through user testimonials, chat rooms and user reviews, perhaps reflecting their relatively high collectivism score on Hofstede's aforementioned typology.

Adapting to such cultural differences is important for e-commerce success [29]. Singh \& Pereira [40] maintain that consumers prefer to shop on and interact with sites that are specially designed for their locale, while in a follow up study Singh, et al [38] found that "culturally adapted web content positively affects user attitudes, site navigation and purchase intention". Luna, Peracchio and de Juan [23] claim that adapting web content to a market's specific needs enhances usability, reach and website interactivity, ultimate leading to higher purchase intent. Thus linguistic translation is only the first step to internationalization [8]. To be effective, a more thorough process of localization, taking into account the political, social, technical and economic conditions of each market, is needed to reconcile global strategies with local cultural and market differences [19].

In practical terms such adaptation can be difficult, requiring an in-depth understanding of the culture, values and norms of each target market [30]. If, for example, the issue of color is considered, white stands for purity in the West, but in India, Japan and several other Asian nations it represents death [26]. Similarly the number four is considered bad luck in numerology obsessed China, while thirteen, usually considered unlucky in Western cultures, is regarded favorably. Even within language groups, different approaches may be necessary. Hispanic consumers within the US differ both the general (English speaking) population, but also differ significantly from other Spanish language speakers in Central / South America or mainland Spain [37]. Even though linguistically they use (more or less) the same language, these important consumer groups cannot to be lumped together, as each demands culturally relevant content adapted to their specific needs.

More practical challenges of localization become apparent when issues such as payment are considered. For example, US websites typically require payment by credit card. However in other regions of the world both credit card penetration and credit card usage are more limited. For example, in China the most common payment method is cash-on-delivery, reflecting the Chinese culture of cash-based payment [6]. Similarly in the Arab world the widespread use of credit and debit card is not readily accepted by the general population for historical and religious reasons [13]. In Germany payment by bank transfer is common, while in Japan consumers typically pay for online purchases at their local grocery store. To operate successfully in such markets, companies must adapt to local conditions, allowing customers to pay using whatever methods are the local norm, as failure to do so means significantly lower online sales. 
Logistics and shipping can also be a challenge in international markets. Unlike in the US where delivery is typically contracted out to relatively efficient private firms such as UPS and FedEx, in many countries the only viable delivery service is the state-owned postal system, which is often notorious for being slow, unreliable and for mishandling goods [6]. To operate successfully in such markets, companies often have to develop their own solutions. In China, for example, as labor is relatively cheap, many large e-commerce companies have implement a hybrid business model, with orders being process online, but deliver being made by company employees who collect cash upon delivered. Flexibility and adaptation to local norms are thus keys to success.

\section{The Global e-Readiness Index}

As adaptation to the needs of different markets is clearly seen as a key success factor in the global e-commerce market, the concept of a Global e-Readiness Index (GRI) has been proposed to evaluate the preparation of company websites to interact with a global audience [3]. In their initial 2004 paper, Augustine and Surynt adapted a macro level concept that had previously been applied to measuring the potential of countries to support e-businesses (see for example [30]). Adjusting this idea for application at the company level, the authors synthesizing prior research to develop the Global Readiness Index (GRI) - a summary statistic designed to show the extent to which individual websites are ready to meet the requirements of operating in a global marketplace.

In their most recent study, the authors have refined their initial model so that the GRI effectively combines five elements: (1) Language - does the website offer languages other than its native language?; (2) Currency - does the website offer currency conversions or the ability to purchase in alterative currencies?; (3) Address - does the website accommodate non-US elements in the purchase address?; (4) Payment does the website allow for payment options other than credit cards?; and (5) Logistics / Shipping - does the website support the use of shipping / logistics systems appropriate to multiple locales [4]. This portfolio of issues is largely supported by other independent studies. For example, Bin, Chen \& Qin Sun [6] maintain that payment, logistic systems and language are the primary factors that every firm should take into account in the process of online globalization. Similarly Fields [14] highlights language, currency and payment options as key issues for hotels wishing to address an international audience, while Lituchy and Barra [23] suggest that websites need to localize in terms of language, address data, number format, date format and postal code in order to be able to work effectively with international audiences.

Calculation of the index score itself is carried out by performing a visual evaluation of the selected websites and assigning values based on how well each satisfies criteria developed using the variables described above, with a score ranging from zero to two (corresponding to low, medium and high) awarded based on the degree to which the specific measure is applied. The GRI is then calculated by simple summation and expressed as a percentage.

\section{RESEARCH METHODOLOGY}

Given the importance of international customers for most hotel companies [20], and the continued growth in the sale of hotel rooms over the Internet, it was decided to extend Augustine, Surynt \& Jen's study to the hotel sector by assess the global e-readiness of the major international hotel chains.

Although the initial intent was to closely follow the same methodology, certain characteristics of the hotel sector necessitated various adjustments, which are summarized in Table One. In particular the fact that hotel rooms are an intangible product, and thus do not require delivery, made the logistics / shipping element irrelevant. In addition, as the literature stressed the importance of localizing not just from a linguistic point of view but also to take cultural preferences into account, a variable was added to incorporate localization. Whether a full or blended approach (i.e. whether the entire website or just a proportion had been adapted linguistically and culturally) was also thought to be important, and thus a variable was added to capture this data. Lastly, given the importance of the reservations process in hotel e-commerce, an in-depth assessment was carried out of each site's booking engine to establish if it too had been translated and localized.

Table 1. Adaptation of GRI Criteria for use in the hotel sector

\begin{tabular}{|l|c|c|}
\hline Issue & Prior study & $\begin{array}{c}\text { Current } \\
\text { Study }\end{array}$ \\
\hline Language & Yes & Yes \\
\hline Localisation & No & Yes \\
\hline Full Content & No & Yes \\
\hline Bookings Engine & No & Yes \\
\hline Currency & Yes & Yes \\
\hline Address elements & Yes & Yes \\
\hline Payment options & Yes & Yes \\
\hline Logistics / Shipping & Yes & No \\
\hline
\end{tabular}

The population for the study was defined as the consumer websites of the top fifty global hotel chains as identified in Hotels Magazine ranking of January 2008. Actual assessment as carried out by three trained researchers during June 2008. Each researcher assessed each of the selected sites independently, scoring each variable using pre-established criteria. Their assessments were subsequently combined and differences highlighted. These elements were then re-examined collectively by the assessors and consensus achieved as to the most appropriate score.

In each case, assessment began with the brand's .com website. Initially the home page was reviewed to establish links to either country specific or international versions of the site to determine the number of languages available. Following the procedure outlined by Raisinghani \& Beldona [30], alternative versions (specifically a French and / or Chinese version if they existed) were explored by comparing the pages generated by clicking on the top level menu systems to establish if alternative versions of the site were full content (i.e. they contained broadly the same content sections, features and facilities as the English version) and to see if the 
non-English content had been localized (by the inclusion of distinctive looks or colors, special offers, images, local personas or text specifically targeted to the local market).

The booking engine (where present) was assessed in detail. Initially it was explored to establish if its pages were available in the alternative languages. The format in which the date needed to be entered (dd-mm-yy vs. mm-dd-yy) was also noted. A trial reservation was then made to examine the rate descriptions displayed by the system. Unlike the bookings engine's web pages themselves, these do not generally form part of the website code but are instead pulled dynamically from the chain's Central Reservation System. Thus, in some cases, while the user interface is displayed in the alternative language, the rate description (including important details such as booking conditions and cancellation restrictions) often reverts back to English.

Whether the rates displayed could be automatically translated by the system into alternative currencies was also assessed. Two different possibilities were noted here - the option to have the rates displayed into the currency of the user's choice, or the provision of a link to a currency converter to allow the user to perform such conversions for themselves on an ad-hoc basis on a third party website. The range of payment methods allowed was also noted. As was discussed previously, although credit cards are common in most countries, certain regions have traditionally preferred alternative forms of payment. For example, German / Swiss clients often prefer to pay by bank transfer, while charge cards such as Switch are widely used as a payment method in the U.K.

Lastly the address data that needed to be entered to complete the reservation was tested to establish if a zip / postal code was mandatory. Such codes are not ubiquitous, and requiring their entry can prevent international clients from completing a reservation. In some cases, validity checks are used on zip codes to insure that they match the address data, in effect making the entry of a false code (such as 00000) to complete the reservation process impossible.

For each variable, the presence / absence of the respective features was noted on the websites under assessment. The resulting data was then analyzed using SPSS to generate descriptive and non-parametric statistics, the results of which are presented below. As in the Augustine, Surynt \& Jen study [4], each site's GRI was calculated by a simple summation of the individual variable scores, although as will be discussed later a more complex calculating, taking into account the relative importance of each variable, would be more appropriate.

\section{FINDINGS}

Given their importance for interacting with international clients, it's not surprising that hotel websites are multilingual in nature. On average, websites were available in five different languages (Mean $=5.14$, standard deviation $=3.70$ ). However the findings are positively skewed, with the majority of sites offering a lower number of options, and only a small number of sites offer a very high number of options. In addition, nearly one quarter of hotel chain websites (24\%) provided information only in English.

Where sites were available in alternative languages, over half (56\%) were full content, with another twenty percent using a blended approach, provide some content in the additional language(s), but either omitting pages and / or linking back to English for some features. In the vast majority of cases (90\%), the non-English language content had been localized with the inclusion of offers, features and other material specifically targeted to the market. Where the site was offered in a language other than English, in most cases (79\%) the user interface of the bookings engine had also been translated into the alternative language. However, as the user dug deeper into the reservation process, the degree of adaptation to international markets fell significantly. Only $60 \%$ provided full rate descriptions in alternative language(s), with the remainder reverting to English for this key data. During the reservation process, over one third $(34 \%)$ of sites required that dates be entered in US format, and nearly two-thirds (60\%) required the entry of a zip / postal code in order to complete the reservation process. Payment options were similarly limited, with nearly three-quarters of sites only accepting the basic options of Visa / MasterCard or American Express.

Table 2. Cluster Analysis

\begin{tabular}{|c|c|c|c|c|}
\hline Cluster & 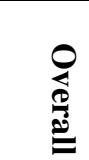 & $\stackrel{\varrho}{\stackrel{\Omega}{\tilde{E}}}$ & $\sum_{0}^{\frac{2}{E}}$ & 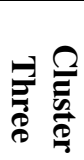 \\
\hline Sizes & 50 & 6 & 15 & 29 \\
\hline \multicolumn{5}{|l|}{ Means } \\
\hline Languages & 2.0 & 3.0 & 2.8 & 1.3 \\
\hline Localization & 0.7 & 0.8 & 1.0 & 0.5 \\
\hline Full Content & 1.3 & 1.4 & 1.7 & 1.1 \\
\hline Bookings Engine & 0.6 & 0.0 & 0.9 & 0.5 \\
\hline Date format & 0.3 & 0.0 & 0.1 & 0.5 \\
\hline Rate Description & 0.4 & 0.0 & 0.5 & 0.5 \\
\hline Currency & 1.1 & 1.2 & 1.1 & 1.1 \\
\hline Zip & 0.4 & 0.0 & 0.0 & 0.7 \\
\hline Payment & 1.3 & 1.4 & 1.5 & 1.2 \\
\hline \multicolumn{5}{|l|}{ Variances } \\
\hline Languages & 1.6 & 0.0 & 0.3 & 1.7 \\
\hline Localization & 0.2 & 0.2 & 0.0 & 0.3 \\
\hline Full Content & 0.7 & 0.3 & 0.2 & 0.9 \\
\hline Bookings Engine & 0.2 & 0.0 & 0.1 & 0.3 \\
\hline Date format & 0.2 & 0.0 & 0.1 & 0.3 \\
\hline Rate Description & 0.3 & 0.0 & 0.3 & 0.3 \\
\hline Currency & 0.8 & 0.2 & 0.7 & 1.0 \\
\hline Zip & 0.2 & 0.0 & 0.0 & 0.2 \\
\hline Payment & 0.4 & 0.8 & 0.4 & 0.4 \\
\hline
\end{tabular}


A cluster analysis was carried out to identify similarities among the companies studied. As can be seen from Table Two, three distinct clusters emerged. The first, dubbed Partials, contained six observations and was composed of companies that provided multiple languages on their website, in general provided fully localized content on these pages, but whose booking engine was only available in English. Rate descriptions were thus only offered in English, and currency conversion facilities (where provided) were external links rather than integrated into the site. Zip codes were required from those making reservations, and payment methods were limited. The second cluster, dubbed Globals, contained 15 observations and was composed of companies with multi-lingual, full content localized websites. However, in contrast to the Partials, these companies also provided their bookings engine in multiple languages, down to the rate description level. The largest cluster, dubbed Locals, contained 29 observations and was composed of companies that offered their website in a more limited number of languages, provided limited content in other languages and made little attempt to localized their offering. Such companies were in general less well adapted to international markets, requiring, for example that zip codes be entered and accepting few alternative payment methods.

As in prior studies, the above variables were combined to generate a Global e-Readiness Index (GRI). For hotel chain websites as a whole, the index figure was 55\%, indicating that collectively these sites are not well adapted to cater to international clientele. However averages can be deceptive, as in fact the GRI scores ranged from $13 \%$ to $80 \%$, with a standard deviation of $22 \%$, indicating wide dispersion. As can be seen from Figure One, the data is negatively skewed $(-0.68)$, indicating that while many sites had high scores, a tail of lower performing companies negatively affected the average.

Post-hoc analysis of the results revealed that many of the sites with lower scores were US focused hotel chains, and that their performance was having a negative effect on overall findings. To test if this difference was statistically significant, the data were split into two groups - that of US hotel chains (defined as those having their corporate headquarters within the US) and international chains (those with their headquarters in other countries).

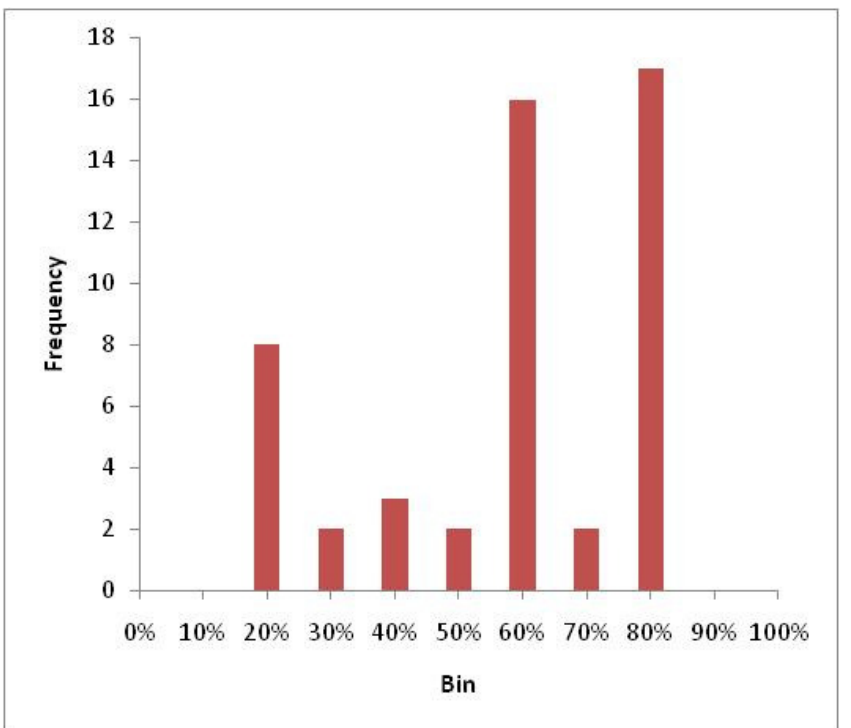

Figure 1. Frequency Distribution of the Global e-Readiness Index Amongst International Hotel Chains

As can be seen from Table Three, the GRI for these two grouping differs greatly, with the difference being significant at the $99 \%$ confidence level. Similarly it was postulated that economy hotels tended to have a lower GRI than other types of hotels, as such chains generally tend to be limited to a single geographic region. Again this assumption was tested by comparing the mean scores for the two groups. As expected, full service hotel chains had significantly higher GRIs ( $>0.05$ ) than their economy sector colleagues, as can be seen from Table Three.

Table 3. T-Test findings

\begin{tabular}{|l|l|l|l|}
\hline GRI & n & Mean & Significant \\
\hline Overall & 50 & $55 \%$ & \\
\hline & 35 & $50 \%$ & \\
\hline $\begin{array}{l}\text { Headquarters } \\
\text { in the U.S. }\end{array}$ & 15 & $67 \%$ & $\mathrm{p}>0.01$ \\
\hline $\begin{array}{l}\text { Headquarters } \\
\text { outside the } \\
\text { U.S. }\end{array}$ & 23 & $49 \%$ & \\
\hline $\begin{array}{l}\text { Economy } \\
\text { sector }\end{array}$ & 27 & $62 \%$ & $\mathrm{p}>0.05$ \\
\hline Other & & & \\
\hline
\end{tabular}




\section{CONCLUSION}

For companies truly wishing to serve a global customer base, adapting their website to take into account the language, culture and social norms of local marketplaces has become a key issue. This study benchmarks the efforts of the top fifty hotel chains to incorporate appropriate content and facilities on their website as an indicator of their commitment to servicing international markets.

Both the individual findings and the summary Global e-Readiness index suggest that at present the major hotel chains are not very global in their e-commerce efforts. While many provide content in languages other than English, in most cases the spectrum of pages available in the alternative language is limited. Even the "best" performers often fail to take their internationalization efforts deep enough into the purchase process to allow non-Anglophone customers to complete reservations in their native languages and using local norms. As can be seen from the cluster analysis, the majority of companies had sites that targeted the market of their country of origin, and made few concessions to addressing international audiences. US companies in particular perform badly; having in effect generic websites that fail to address linguistic, cultural or other internationalization issues, despite the importance of non-Anglophone and non-Caucasian audiences within their key market.

In light of the changing consumer landscape of e-commerce, and in particular the increasing percentage of non-English speaking web users, such an approach is short sighted and puts such companies at a disadvantage. Hotel companies wishing to take advantage of the continued growth in online travel sales need to become more proactive about incorporating appropriate culturally adapted content and facilities into their sites to effectively address the needs of their target markets. This should include not only linguistic elements to go far deeper and address the more ingrained cultural elements of each segment. Localization needs to become the norm rather than the exception.

As with most research, this study suffers from several limitations. Firstly, websites by their very nature are dynamic, but were assessed at only a single point in time. A longitudinal approach would not only overcome this limitation, and would also allow how (or if) website design and content are evolving to be assessed. Secondly, the focus on hotel chain websites means that results cannot be generalized to the industry as a whole, and indeed a similar study of independent hotels in particular might generate very different results. However, prior studies in technology adoption have argued that it is the major chains that have the budget, expertise and global presence to engage in e-commerce in a professional manner and thus studying their performance gives a useful indicator of best practice in the industry as a whole. In a related issue, the use of brand websites in the study means that the performance of certain companies may be unduly influencing the results. Several hotel companies (e.g. Accor Hotels \& Resorts, Wyndham Worldwide) own multiple brands within the list of top fifty hotel companies. In such cases back end technology is often shared across such brands, meaning that the content and facilities provide on their brand websites may be similar and thus may have biased the findings due to double counting. To overcome these two challenges, a larger scale study, using a more representative sample of the industry as a whole, should be undertaken to more accurately benchmark current industry practices.

Finally, the GRI, as it is currently implemented, assigns equal weight to each of the variables assessed, which is unrealistic. In reality certain variables (such as, for example, the availability of several languages, or having localized content) would have a more significant effect on the usability and acceptance of a website by international clients than others (such as, for example, the date format required). A more appropriate weighting system, taking the relative importance of each issue into account, needs to be developed and empirically tested. Multi-country consumer based research could be used to address this question. Such a study would turn the GRI into a more powerful assessment tool, and would be invaluable in helping companies focus their localization and globalization process.

\section{REFERENCES}

[1] Aladwani, A (2003) Key Internet characteristics and e-commerce issues in Arab countries. Information Technology and People, 16 (1), p 20-32.

[2] Augustine, F.K. \& Surynt, T. J. (2004) Assessing the Global Content of E-Commerce Web Sites: A Study of US Based E-Business. The E-Business Review, Vol. 4, p 16-19. [3] Augustine, F.K. \& Surynt, T. J. (2007) Assessing the Indicators of E-Commerce Globalization: A Study of the Characteristics of Global Readiness. The E-Business Review, Vol. 7, p 44-47.

[4] Augustine F.K., Surynt T. J. \& Jens, W. J. (2008) Global Readiness of E-Business Web Sites: An Industry Perspective. The E-Business Review, Vol. 8, p 33-36.

[5] Baker, S. (1999) Global E-Commerce, Local Problems. Journal of Business Strategy, July / August, p 32-38.

[6] Bin, Q, Chen, S \& Qin Sun, S (2003) Cultural Differences in E-Commerce: A Comparison between the U.S. and China. Journal of Global Information Management, 11 (2), p 48-55. [7] Bonanni, C. \& Cyr, D (2004) Trust and Loyalty: A Cross Cultural Comparison, International Conference of Business, Economics and Management Disciplines. Fredericton, New Brunswick.

[8] Bingi, P, Min, A \& Khamalah, J (2000) The Challenges Facing Global E-commerce. Information Systems Management, Fall, p 26-34.

[9] Chau, P, Cole, M, Massey, A, Montoya-Weiss, M \& O'Keefe, R (2002) Cultural Differences in the Online Behaviour of Consumers. Communications of the ACM, 45 (10), p 138-143.

[10] De la Torre, J, Moxon, R (2001). Introduction to the symposium e-commerce and global business: the impact of the information and communication technology revolution on the conduct of international business. Journal of International Business Studies 32 (4), 617-639. 
[11] Del Galdo E \& Neilson, J (1996) International User Interfaces. John Wiley \& Sons, New York.

[12] Dong, J \& Salvendy, G (1999) Designing Menus for the Chinese Population: horizontal or vertical? Behaviour \& Information Technology, 18 (4), p 467-471.

[13] Elbeltagi, I (2007) E-commerce and globalization: an exploratory study of Egypt. Cross Cultural Management: An International Journal, 14 (3), p 196-201.

[14] Fields, B (2009) Global Marketing: Does One Size Fit All? HSMAI News, 26 March 2009.

[15] Friedman, T (2005) The World is Flat 3.0: A Brief History of the Twenty-First Century. Picador, New York, New York.

[16] Good, D \& Schultz, R (2002) e-Commerce Strategies for Business-to-Business Service Firms in the Global Environment. American Business Review, June, p 111-118.

[17] Hofstede, G (1997) Cultures and Organisations: Software of the Mind. McGraw-Hill, New York.

[18] Huizingh, E (2000) The content and design of web sites: an empirical study. Information \& Management 37 (2000) 123-134.

[19] Hwang, W. Jung, H.S. \& Salvendy, G (2006) Internationalization of e-commerce: a comparison of online shopping preferences among Korean, Turkish and US populations. Behaviour \& Information Technology, 25 (1), p 3-18.

[20] Jeong, M \& Lambert, C (2001) Adaptation of an information quality framework to measure customers' behavioural intentions to use lodging websites. International Journal of Hospitality Management, 20, 129-146.

[21] Ju-Pak, K (1999) Content dimensions of web advertising: a cross-national comparison, International Journal of Advertising, 18 (2) p 207-31.

[22] Kim, S \& Lee, Y (2006) Global online marketplace: a cross-cultural comparison of website quality. International Journal of Consumer Studies, 30 (6) p 533-543.

[23] Luna, D Peracchio, A \& de Juan, M (2002) Cross-Cultural and Cognitive Aspects of Website Navigation. Journal of the Academy of Marketing Science, 30 (4), p 397-410.

[24] Lynch, P \& Beck, J (2001) Profiles of internet buyers in 20 countries: evidence for region-specific strategies. Journal of International Business Studies 32 (4), 725-748.

[25] Marcus, A \& West-Gould, E (2000) Crosscurrents: Cultural Dimensions and Global Web User Interface Design. Interactions, July / August, p 32-46.

[26] Mitchell, A (2000) Global brands or global brands? Journal of Consumer Studies, 24 (2) p 85-93.

[27] Murphy, J \& Scharl, A (2007) An investigation of global versus local online branding. International Marketing Review, 24(3): 297-312.

[28] Nielsen, J (1990) Designing User Interfaces for International Use. Elsevier Science Ltd, New York.

[29] Park C \& Jun, J (2003) A cross-cultural comparison of Internet buying behavior effects of Internet usage, perceived risks and innovativeness. International Marketing Review, 20 (5), p 534-553.

[30] Raisinghani, M \& Beldona, S (2003) Global E-Readiness of Web Sites: A look at the Top 50 Global Companies. Journal of International Business and Entrepreneurship
Studies, 1 (2), p 102-108.

[31] Robles, F (2002) The evolution of global portal strategy. Thunderbird International Business Review 44 (1), 25-46.

[32] Robbins, S \& Stylianou, A (2003) Global corporate websites: an empirical investigation of content and design. Information \& Management, 40, p 205-212.

[33] Seidenspinner, M \& Thuner, G (2007) Intercultural Aspects of Online Communications: A Comparison of Mandarin-Speaking, US, Egyptian and German User Preferences. Journal of Business Economics and Management, 8 (2), p 101-109.

[34] Sagi, J (2004) ICT and business in the new economy: globalization and attitudes towards ecommerce. Journal of Global Information Management, 12 (3) p 44-65.

[35] Sarkar, M \& El Sawy, O (2003) The Four Tigers if Global E-Business Infrastructure: Strategies and Implications for Emerging Economies. Communications of the Association for Information Systems, 12, p 1-22.

[36] Simon, S (2001) The impact of culture and gender on web sites: an empirical study. The DATA BASE for Advances in Information Systems, 32 (1), p 19-37.

[37] Singh, N, Baack, D, Pereira, A \& Baack, D (2008) Culturally Customizing Websites for U.S. Hispanic Online Consumers. Journal of Advertising Research, June, $\mathrm{p}$ 224-234

[38] Singh, N, Fassott, M, Chao, C \& Hoffmann, J (2006) Understanding International Website Usage: A Cross-National Study of German, Brazilian and Taiwanese Online Consumers. International Marketing Review, 23 (1) p 83-98.

[39] Singh, N \& Matsuo, H (2004) Measuring cultural adaptation on the Web; a content analytic study of US and Japanese Web sites. Journal of Business Research 57 (8), 864-872.

[40] Singh, N \& Pereira, A (2005) The Culturally Customised Web Site: Customizing Web Sites for the Global Marketplace. Burlington, MA: Elsevier Butterworth Heinemann. 